\title{
VIRTUAL DETERMINATION OF BLOOD GLUCOSE OBTAINED FROM FED RATS AND FROM 24-HOUR FASTED RATS
}

\author{
Vera Maria Treis Trindade ${ }^{1}$, Pablo Ricardo Arantes ${ }^{1}$, Geancarlo Zanatta ${ }^{1}$, Christianne Gazzana Salbego ${ }^{1}$ \\ ${ }^{1}$ Universidade Federal do Rio Grande do Sul, Bioquímica (Rio Grande do Sul, Brasil)
}

INTRODUCTION: The normal blood glucose in rats is $100 \mathrm{mg}$ glucose / $100 \mathrm{ml}$ of blood plasma. After a $24 \mathrm{hhour}$ fast, a decrease around $30 \%$ of this value occurs. This reduction can reach $45 \%$ in a prolonged fast. Several processes controlled by neurohormonal mechanisms prevent a more pronounced decrease in blood glucose of animals subjected to fast. These processes are hepatic glycogenolysis, hepatic gluconeogenesis, decrease of glucose utilization and increase of fatty acids use by muscle tissue, and ketone bodies utilization by the central nervous system. OBJECTIVES: This study presents a learning object, mediated by computer, which simulates the determination of blood glucose (glycemia) obtained from fed rats and from 24-hour fasted rats. MATERIALS AND METHODS: At first, cartoons were planned in order to show the biochemical and methodology fundamentals. The most representative images were selected, edited and inserted into an animation developed with the aid of the Adobe ${ }^{\circledR}$ Flash 8 software. DISCUSSION AND RESULTS: The animated simulation of a standard glucose curve, followed by virtual evaluation of glucose in blood plasma samples were developed, associated with some questions. This object has been used by students of Biochemistry I (Pharmacy-UFRGS) since second semester of 2009. The navigation features, design and interactivity have been evaluated as excellent by about $80 \%$ of them. CONCLUSION: Therefore, this learning object can be considered an adequate teaching resource as well as an innovative support in the construction of theoretical and practical knowledge of Biochemistry. Available at: http://www.ufrgs.br/gcoeb/dosagemglicemia/

Keywords: glycemia; learning object; standard curve simulation 